\title{
Scolecita, Rio Pelotas, RS
}

\author{
RUI RIBEIRO FRANCO
}

(Departamento de Mineralogia e Petrografia, Universidade de S. Paulo)

Em nosso trabalho, "Zeólitas dos basaltcs do Brasil Meridional", Franco (1952), foram feitas referêncies a êsse mineral do grupo das zeólitas e verificou-se ser êle pouso frequente nos basaltos amigdaloidais. Assim, referência foi feita apenas ès ccorrências da Fazenda Palmital (Sertãozinho), SP e Campos Wovcs, rio Canoas e serra Tubarão, $\mathrm{SC}$, com a apresentação de alguns dados morfológicos, físicos e químicos.

O material cbjeto dessa nota fui coletado pelo auíor à margem do rio Pelotas, Estado do Rio Grancie do Sul, onde recentemente foram feitos numerosos cortes no basalto amigdaloidal que constitui o vale do mencionado rio. Aiém das associcções de zeólitas e minerais associados (incluem-se aqui numerosas amigdalas e fendas preenchidas por quartzo, calcedônea e ágata) já mencionados no trabalho referido acima ccorrem também nos basaltos do rio Pelotas numerosas drusas preenchidas predominantemente por grandes massas de cristais fibro-radiados, puros, divergentes e de brilho vítreo, nâs regióes não aiteradas, que analisados òticamente mostraram ser siolecita. $O$ aspecto exibido por êsse mineral é idêníico às formações por nós já descritas para as mesolitas da serra de Bctucatú, Torinha e Sertãozinho, no Estado de São Paulo, Fig. 1.

Exibem nítida clivagem em dues cireções, paralelas às faces do prisma $\{110\}$, com ângulo aproximado de $88^{\prime \prime}$ Os cristais alongam-se por vezes até $10,00 \mathrm{~cm}$ de comprimiento, alguns atingindo $0,7 \mathrm{~cm}$ na secção ncrmal ao comprimento. INão exibem terninações inteiras, isto é, faces de prismas obliquos e pinacó:des. As terminações estão frequentemente fraturadas. A simetria monecínica dos cristais é característica. Não foi encontrado um único cristal simples; todos exibem a invariável geminação segundo a $\{100\}$, geminação observada pela primeira vez por David Brewster, Figs. 2, 3 e 4 . Nem sempre o traço do plano de geminação é uma linha reta ou mesmo quebrada. Muitas 
vezes o traço é uma linha inteiramente sinuosa, irregular, que penetra ora um cristal, ora outro.

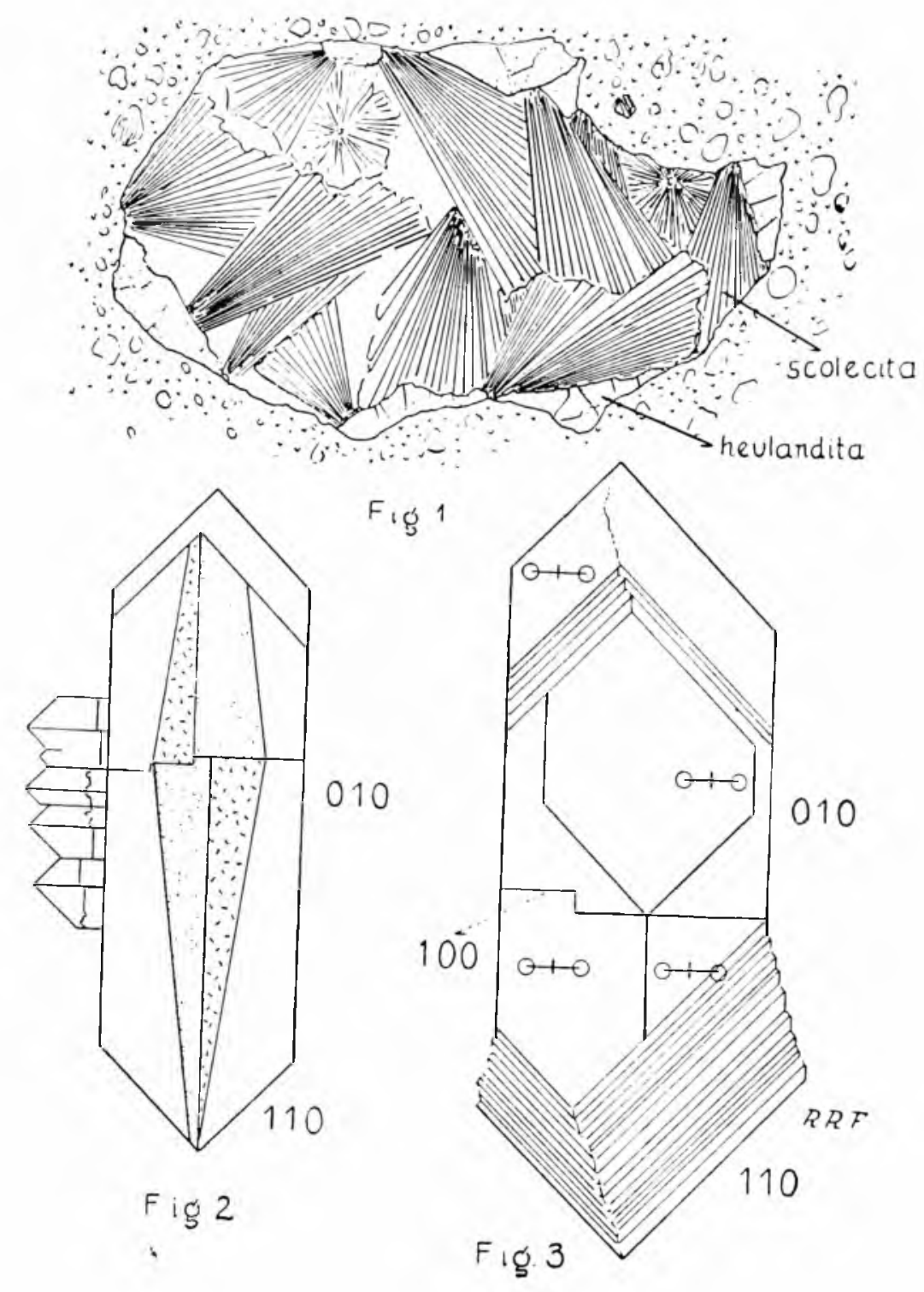

Muitos cristais se apresentam cruzados, isto é, dispostos a $90^{\circ} \mathrm{um}$ do outro, parecendo tratar-se de verdadeira geminação. $O$ prisma $m$ $\{110\}$ é sempre presente. É curioso notar, em alguns cristais das Figs. 3 e 4, um alargamento das suas partes terminais. Esse alargamento é a continuação perfeita das faces do prisma $m$, embora êle se mostre formado por sucessão de pequenas faixas, todas òticamente isorientadas. Às vezes o alargamento se dá de um só lado do cristal. Tudo indica que êsse alargamento, tão bem visível nas figuras mencionadas, seja consequência de crescimento secundário, sôbre cristais anteriormente formados. Isso leva a crêr que pelo menos dois tempos de crescimento ocorreram durante o processo de cristalização da scolecita. 
A segunda fase de crescimento parece corresponder a nítida combinação oscilatória entre as faces de $\{010\}$ e $\{110\}$, como se vê nas Figs. 3 e 4 .

Os cristais tabulares, alongados, mostram todos os graus de alteração até a sua transformação completa em pó branco, que se desfaz à maneira de caulim.

Em um caso foi fácil verificar que um dos cristais apresentava-se corroido e na área da reabsorção precipitaram-se numerosos e minúsculos cristais orientados diversamente.

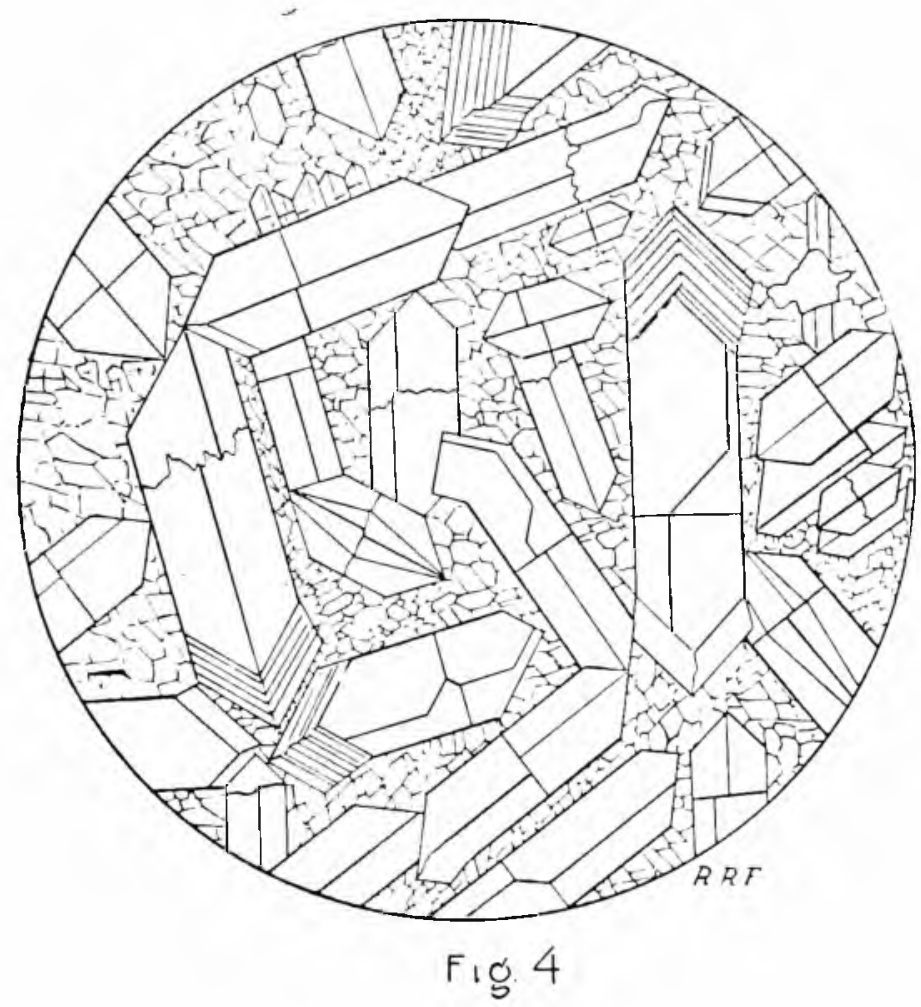

Secção delgada de um feixe aproximadamente paralelo de cristais de scolecita. Notar cristais geminados bem desenvolvidos e cristais menores. Alguns cristais exibem crescimento secundário. $19 \mathrm{x}$.

Em preparado algum pudemos reconhecer a associação scolecitaokenita, como sugere Michell (1911, pag. 494), que afirma nunca ocorrer a scolecita isolada.

O pêso específico de material comprovadamente puro, isento de alteração e inclusões e determinado pelo método da balança é o seguinte:

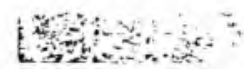

$$
\begin{aligned}
& \text { a } 20^{\circ} \mathrm{C}-2,274 \pm 0,008 \text { (êrro provável) } \\
& \text { a } 4^{\circ} \mathrm{C}-2,262 \pm 0,003 \text { (êrro provável) }
\end{aligned}
$$


Os cristais apresentam-se inteiramente incolores e birrefringência baixa, $\eta$ Y $(1,519)-\eta \propto(1,512)=0,007$. O valor do índice de refração intermediário é $r_{i} \beta=1,518$.

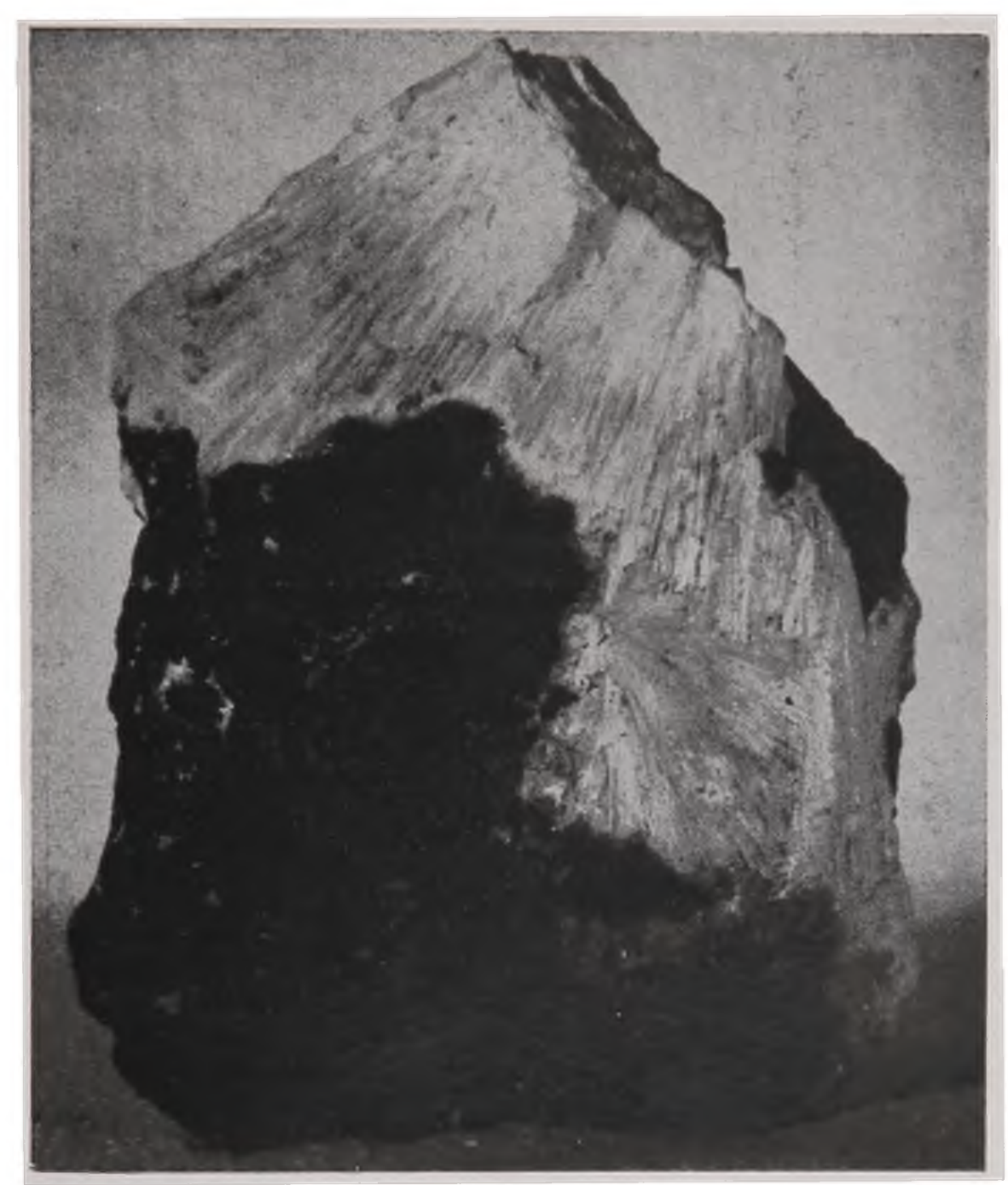

Feixes divergentes de cristais de scolecita em basalto amigdaloidal.

Os cristais apresentam elongação negativa e os ângulos de extinção nas secções longitudinais, medidos em numerosos cristais apresentaram os valores seguintes:

$$
\begin{array}{ll}
9^{\circ} & -\quad 14^{\circ} 10^{\prime} \\
13^{\circ} 30^{\prime} & -25^{\circ} 10^{\prime} \\
9^{\circ} 30^{\prime} & -11^{\circ} 30^{\prime} \\
14^{\circ} & -19^{\circ} 30^{\prime} \\
13^{\circ} & -20^{\circ} \\
13^{\circ} 30^{\prime} & -25^{\circ} 10^{\prime} \\
14^{\circ} & -20^{\circ} 50^{\prime}
\end{array}
$$


A variação dos valores angulares se deve, provàvelmente, ao fato de não ter sido possível isolar secções perfeitamente normais a $\{010\}$, dada a clivagem distinta segundo $\{110\}$.

As secções normais ao comprimento dos cristais tabulares exibem a geminação característica.

A extinção não é paralela ao traço de geminação, variando de indivíduo para outro. Os dados abaixo foram cbtidos estudando cristais cortados normalmente ao comprimento, onde é fácil a verificação das faces de prismas e o traço do plano de $\{100\}$, plano de geminação:

\begin{tabular}{|c|c|c|c|c|c|c|}
\hline $1 .^{\circ}$ indivíduo & 一 & $26^{\circ} 30^{\prime}$ & , & 2. ${ }^{\circ}$ indivíduo & 一 & $\begin{array}{l}20^{\circ} \\
0^{\circ} 30\end{array}$ \\
\hline$"$ & - & $21^{\circ}$ & & $"$ & & $\begin{array}{r}9^{\circ} 30 \\
\end{array}$ \\
\hline$"$ & $\longrightarrow$ & $19^{\circ}$ & & $"$ & & $12^{\circ} 30$ \\
\hline
\end{tabular}

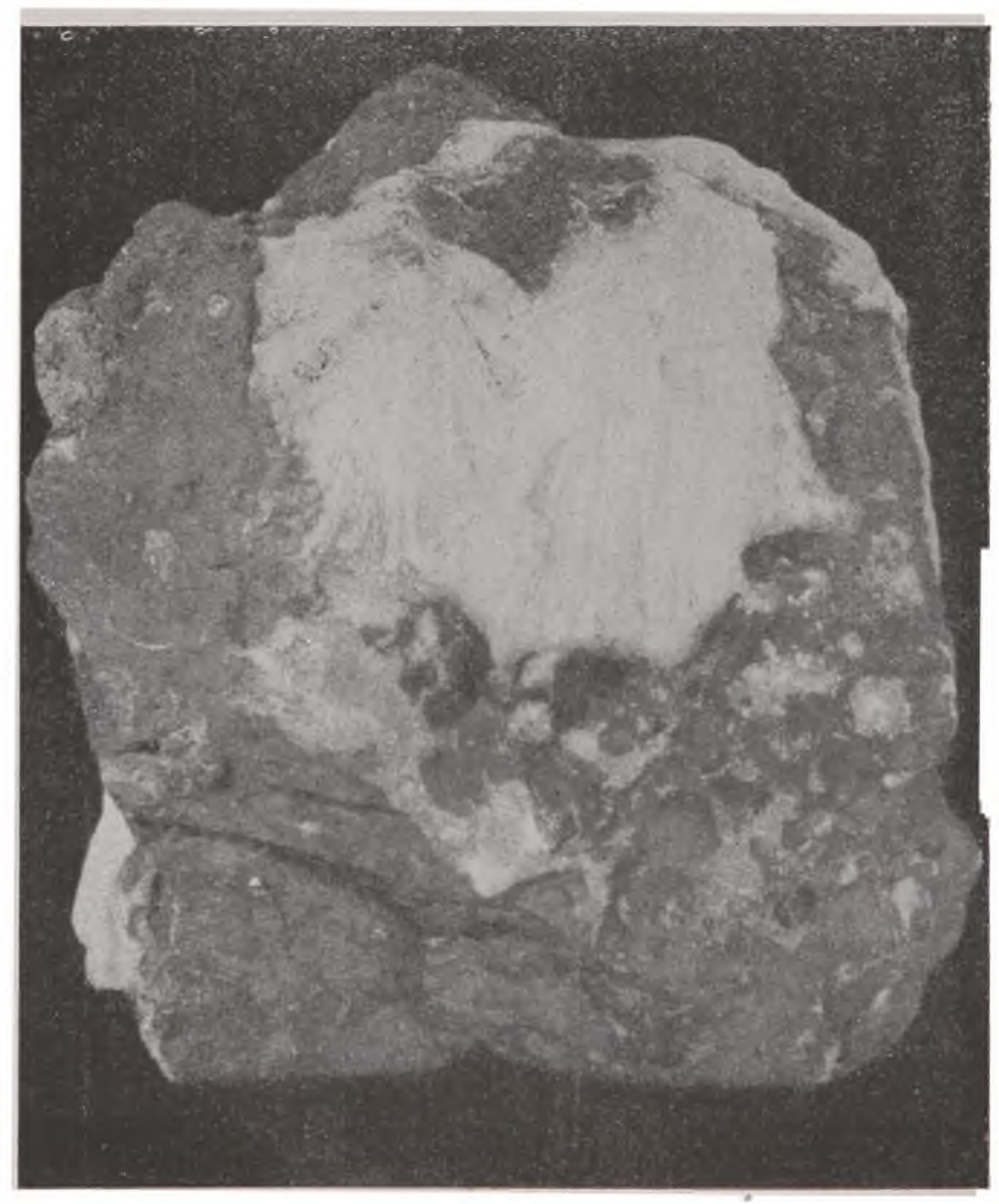

Basalto amigdaloidal do rio Pelotas, com numerosas amigdalas contendo heulanditas e scolecita. Aqui, também é facil ver os feixes divergentes de cristais de scolecita. 
A bissetriz aguda (negativa) é quase perpendicular à secção normal às faces do prisma $\{110\}$, Fig. 3.

O ângulo dos eixos óticos é relativamente pequeno. Medido em numerosos cristais, na platina de Federov, tem-se como valor médio:

$$
2 \mathrm{~V}= \pm 36^{\circ}
$$

Muitas secções parecem mostrar anomalias óticas. Dessas são mais comuns as seguintes: diferentes ângulcs de extinção nas duas partes do geminado, mesmo quando as duas metades são igualmente orientadas, e divisão dos indivíduos que se geminam em diferentes campos, apresentando comportamentos diversos. Em muitos geminados verificou-se que as partes cpostas, pertencentes a individuos diferentes, apresentam extinção simultârea. Contudo, isso não é a regra. Extinção ondulante é muito comum nos cristais.

A scolecita do rio Pelotas contém proporções mínimas de potássio e sódio. Bário e estrôncio não foram identificados na análise química.

\section{BIBLIOGRAFIA}

\section{Citada}

Franco, R. R. (1952), Zeólitas dos basaltos do Brasil meridional: Bol. Fac. Fil. Ci. Let. n. ${ }^{\circ}$ 150, Mineralogia $n^{\circ} 10$, pp 1-69.

Michell, H. (1911), Ein neues Zeolithvorkommen im böhmischen Mittelgebirge: Tschermak Min. Petr. Mitt., vol. 30, pp. 482-496.

\section{Consultada}

Gorgey, R. (1909), Über Mesolith: Tschermaks Min. Petr. Mitt., vol. 28, pp. 77-105.

Haüy, R. J. (1801), Traité de Min. (Paris), vol. 3, p. 159.

Hey, M. H. (1936), Studies on the zeolites. Part IX. Scolecite and Metascolecite: Min. Mag., vol. XXIV, n. ${ }^{\circ}$ 152, pp. 227-253.

Hussak, E. (1890), Notas sobre zeolitas do augito-porphyrito de São Paulo e Sania Catarina: Bol. Ccm. Geogr. Geol., E. de São Paulo, n. ${ }^{\circ}$, pp. 244-251.

KALB, G. (1932), Die Vizinalerscheinungen auf den Hauptformen der Skolezitkristalle: Zeits. Kryst., vol. 81, pp. 243-247, 333-351. 
LaCrolx, A. (1885), Sur le diagnostic des zéolithes en l'absence de for 4 mes cristallines determinables: Bull. Soc. Min. France, vol. 8, pp. 321-365.

Luedecke, O. (1881), Mesolith und Skolezit: Neues Jahrb.. Min., vol. 2, pp. 1-41.

Rinne, F. (1894), Beitrag zur Kenntniss des Skolezits: Neues Jahrb. Min., vol. 2, pp. 51-68.

RinNe, F. (1923), Bemerkungen zur Röntgenographie des Skolezits und Metaskolezits: Neues Jahrb. Min., Beil. — Bd. 48, p. 240.

Schmidt, C. (1886), Beiträge zur Kenntniss des Skolezit: Zeits. Kryst. Min., vol. 11, pp. 587-596.

Stoklossa, G. (1918), Über die Natur des Wassers in den Zeolithen: Neues Jahrb. Min., Beil. - Bd. 42, p. 1.

TAYlOR, W. H., Meek, C. A. e Jackson. W. W. (1933), The structure of the fibrous zeolites: Zeits. Kryst., vol. 84, pp. 373-398.

Thugutr, S. J. (1948), Zeolites: Chemical properties and origin: An. Soc. Geol. Pologne, vol. XVIII, pp. 5-35.

ZephaRovich, V. von (1884), Skolezitkrystalle aus Island: Zeits. Kryst. Min., vol. 8, p. 588.

Winchell, A. N. (1925), A new theory of the composition of the zeolites, Part II: Am. Min., vol. 10, pp. 112-117.

Wyart,J. (1933), Recherches sur les zéolites: Bull. Soc. Franç. Min., vol. 56, pp. 81-188. 